\title{
A cohort study of ethnic differences in use of adjuvant chemotherapy and radiation therapy for breast cancer in New Zealand
}

\author{
Sanjeewa Seneviratne ${ }^{1,3^{*}}$, Ian Campbell ${ }^{1}$, Nina Scott ${ }^{2}$ and Ross Lawrenson ${ }^{1}$
}

\begin{abstract}
Background: Ethnic and socioeconomic inequities in use of breast cancer adjuvant therapy are well documented in many countries including the USA, and are known to contribute to lower breast cancer survival among minority ethnic and socioeconomically deprived women. We investigated ethnic and socioeconomic inequities in use of adjuvant radiotherapy and chemotherapy in a cohort of women with invasive breast cancer in New Zealand.

Methods: All women with newly diagnosed invasive breast cancer during 1999-2012 were identified from the Waikato Breast Cancer Register. Rates of chemotherapy use and radiotherapy use were assessed in women who were deemed to be eligible for chemotherapy $(n=1212)$ and radiotherapy $(n=1708)$ based on guidelines. Factors associated with use of chemotherapy and radiation therapy were analysed in univariate and multivariate regression models, adjusting for covariates.

Results: Overall, rates of chemotherapy and radiotherapy use were 69\% $(n=836)$ and $87.3 \%(n=1491)$, respectively. In the multivariate model, significantly lower rates of radiotherapy use were associated with Māori compared with NZ European (Odds Ratio $[O R]=0.63,0.40-0.98)$, presence of comorbidity $(O R=0.49,0.34-0.72)$, distance from hospital of over $100 \mathrm{~km}(\mathrm{OR}=0.47,0.23-0.96)$, mastectomy compared with breast conserving surgery $(\mathrm{OR}=0.32,0$. 17-0.56) and non-screen compared with screen detection ( $O R=0.53,0.35-0.79)$. No significant associations were observed between chemotherapy use and ethnic or socio-demographic factors.

Conclusions: Improving access for radiotherapy, especially for women who are at a higher risk of not receiving optimum cancer therapy due to ethnicity, geography or socioeconomic status need to be recognized as a priority to reduce inequities in breast cancer care in New Zealand.
\end{abstract}

Keywords: Breast cancer, Chemotherapy, Radiation therapy, Ethnicity, Inequity

\section{Background}

Disparities in breast cancer survival by ethnicity and socioeconomic status are well documented in many countries [1-4]. As in the USA, poor healthcare access among ethnic minority or Indigenous and socioeconomically deprived women has been shown to be a major factor for such breast cancer survival disparities [2]. Differences in quality and timeliness in treatment of breast cancer, including differences in the use of adjuvant therapy have also been reported to be important

\footnotetext{
*Correspondence: sanjeewa_sa@yahoo.com

'Waikato Clinical School, University of Auckland, Hamilton, New Zealand

${ }^{3}$ Department of Surgery, University of Colombo, Colombo, Sri Lanka

Full list of author information is available at the end of the article
}

contributors for ethnic and socioeconomic disparities in breast cancer survival $[1,5,6]$.

Indigenous Māori in New Zealand are known to have lower access, receive inferior quality cancer care and experience longer cancer treatment delays compared with non-Indigenous NZ Europeans for a variety of cancers [7-10]. For instance, Māori patients have been reported to experience longer delays for surgical treatment of breast and lung cancer, and to have a lower likelihood of receiving chemotherapy for bowel cancer compared with NZ European patients [7, 8]. Breast cancer mortality rate in Māori is $60 \%$ higher compared with NZ European women, and more advanced cancer stage at diagnosis in Mãori has been shown to be the 
major factor towards this disparity [11]. However, data are sparse on possible ethnic differences in use, quality or timeliness of adjuvant therapy for breast cancer in New Zealand.

New Zealanders receive healthcare through a mixture of public and privately-funded services. Publicly funded health service is well resourced and provides free specialist and hospital care to all citizens. Private health care facilities run parallel to the public and are mostly funded through insurance schemes. BreastScreen Aotearoa (BSA) is the national breast cancer screening programme which provides free biennial breast cancer screening for all women aged 45-69 years. The Waikato District Health Board region has a population of just over 400,000 . It has a major urban centre, a significant rural population and a Māori population of nearly 84,000 [12]. While a majority of women receive surgical care through the public sector a minority receive surgical care through well-equipped private sector hospitals. Oncology services for the region are available only through the public sector. Radiation facilities for the region are provided exclusively through the radiation facility at the tertiary hospital in Hamilton. A majority receive chemotherapy through the same tertiary centre in Hamilton while a minority receive chemotherapy through a satellite facility.

We hypothesized that Māori women were less likely to have received recommended adjuvant chemotherapy and/or radiotherapy compared with NZ European women $[13,14]$, which might have contributed to the higher breast cancer mortality in Māori women. To answer this question, we analysed cancer treatment data from a regional, population based sample of women with newly diagnosed breast cancer over a period of 14 years. Rates of adjuvant chemotherapy and radiotherapy use by socio-demographic and tumour characteristics were analysed individually, and adjusting for covariates, to identify associations between use of adjuvant therapy, and sociodemographic characteristics.

\section{Methods}

\section{Study population}

Data for this study were extracted from the Waikato Breast Cancer Register (WBCR), a prospective database of newly diagnosed breast cancers in the Waikato, New Zealand since 1999. Completeness and accuracy of the WBCR data have been validated previously [15]. All women with newly diagnosed primary invasive breast cancer during the period from 01/01/1999 through 31/12/ 2012 , were identified from the WBCR $(n=2848)$. Of this, women with metastatic cancer at diagnosis $(n=166)$ and women who did not undergo primary surgery $(n=114)$ were excluded.

\section{Data}

Patient ethnicity was obtained from the WBCR which records self-assigned ethnicity and was grouped into four categories; Māori, Pacific, NZ European, and Other. Cancer staging was performed according to TNM (Tumour, Lymph node and Metastasis) staging system [16].

Socioeconomic status was categorized according to New Zealand Deprivation Index 2006 (NZDep06) [17]. NZDep06 measures socioeconomic status based on area of residence and assigns a deprivation score on a scale from 1 to 10 (1-least deprived 10\% of areas, 10-most deprived $10 \%$ of areas in NZ) based on nine socioeconomic parameters. Distance to treatment facility where surgery was carried out was calculated based on patients' residential address and was categorized in to four categories; $0-10 \mathrm{~km}, 10-50 \mathrm{~km}, 50-100 \mathrm{~km}$ and $>100 \mathrm{~km}$. A comorbidity score for each woman was calculated using Charlson Comorbidity Index [18], based on existing comorbidities at the time of diagnosis of breast cancer. Comorbidity score was categorized into 0 or $\geq 1$.

\section{Use of adjuvant therapy Chemotherapy}

Chemotherapy eligibility was considered only for women younger than 70 years. Of the women considered to be eligible for chemotherapy $(N=1212)$, women who received either adjuvant or neo-adjuvant chemotherapy were considered to have received chemotherapy. For oestrogen (ER) and progesterone (PR) receptor negative cancers, a maximum tumour diameter of $\geq 10 \mathrm{~mm}(n=276,22.8 \%)$ was considered as the threshold for chemotherapy (Fig. 1). For ER and/or PR positive tumours, defining a threshold for chemotherapy was complicated as this decision in most situations was based on multiple factors including lymph node involvement, tumour grade, lympho-vascular invasion, human epidermal growth factor receptor - type 2 (HER-2) status, and more recently, with Ki-67 and

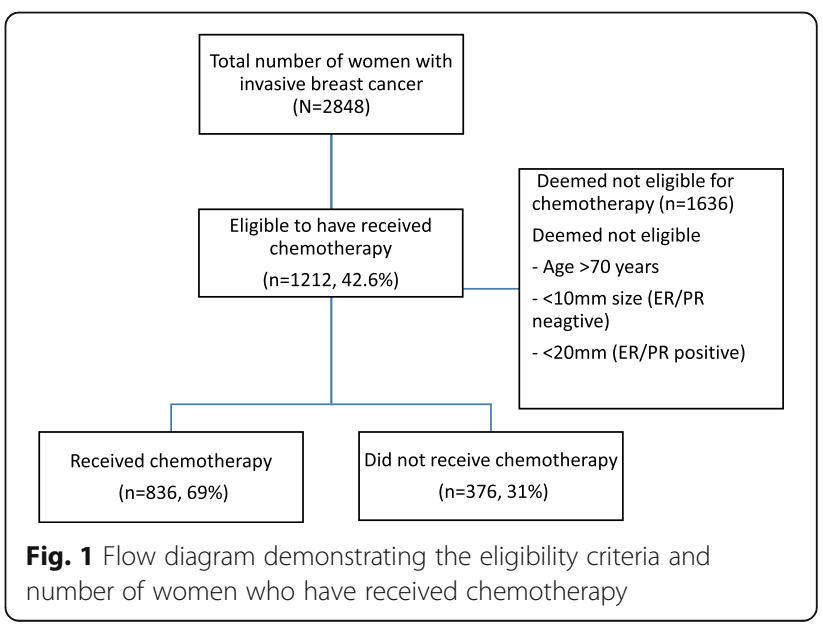


tumour genotyping [19]. For ER and/or PR positive or unknown tumours, we considered $\geq 20 \mathrm{~mm}$ maximum tumour diameter as the threshold for chemotherapy $(n=936,77.2 \%)[13,14]$. We also performed a separate analysis with a different threshold for ER and/or PR positive cancers. For this analysis, women were considered eligible only if one or more of lymph node positivity, tumour grade $\geq 2$ or lympho-vascular invasion were present, in addition to a maximum tumour diameter of $\geq 20 \mathrm{~mm}$.

\section{Radiotherapy}

Women who were deemed to be eligible for radiotherapy $(n=1708)$ were identified based on following criteria (Fig. 2). All women undergoing breast conserving surgery without a completion mastectomy ( $n=1354,79.3 \%)$ were considered eligible, and for women undergoing a mastectomy, if the maximum tumour diameter was $\geq 50 \mathrm{~mm}$ or if $\geq 4$ lymph nodes were positive for tumour metastasis $(n=354,20.7 \%)$ were considered eligible $[13,14]$.

\section{Data analysis}

Data were analysed using SPSS (Version 22) [20]. Chi squared tests $\left(x^{2}\right)$ for trend or Wilcoxson rank test were used to test differences in use of chemotherapy and radiotherapy among groups categorized by age, ethnicity, stage, mode of diagnosis and year of diagnosis. Multivariable logistic regression was used to derive relative odds (odds ratios) of Maori women receiving chemotherapy or radiotherapy compared with NZ European ethnicity adjusted for other factors. Variables were retained in multivariable models if $\mathrm{p}$ values were less than, or equal to the conventional 5\% level, or if they were considered to be of significant clinical or population health importance. Possible interactions between covariates included in multivariate models were not studied.

Ethnic comparisons were performed between NZ European $(n=2303,80.9 \%)$ and Maori $(n=429,15.1 \%)$ populations. Pacific $(n=53,1.9 \%)$ and Asian $(n=63$,

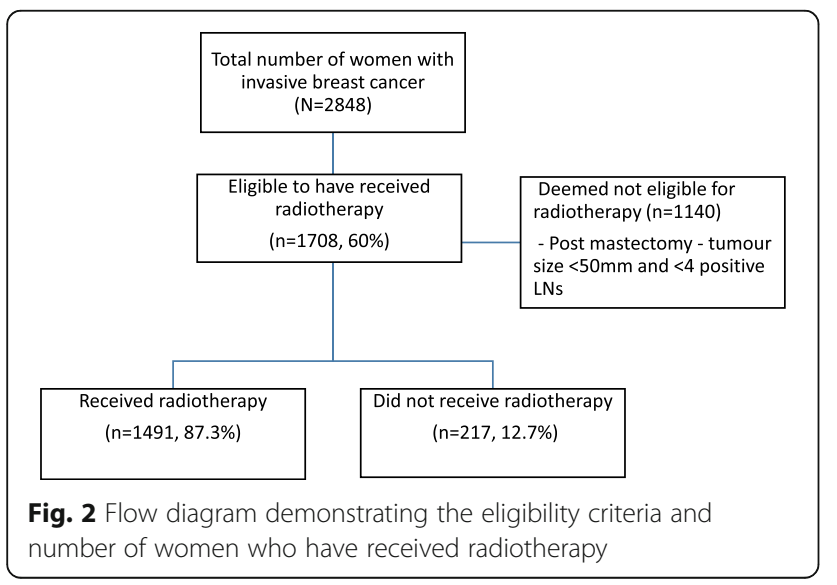

2.2\%) populations were excluded from comparisons due to small sample size.

Logistic regression analyses were performed including only the patients with complete data for all variables of interest. Patients with missing data were excluded from regression models as the missing numbers were relatively small $(<5 \%)$, except for HER-2 status (missing data $23.7 \%)$. Regression analyses for chemotherapy was performed twice; firstly, including missing HER-2 status as a separate category and secondly, excluding cases with missing HER-2 status data. Odds ratios and $\mathrm{p}$ values between the two models were found to be almost identical. The model with missing data as a separate category is shown in this report. Imputation of missing values was not undertaken due to the similarity of these results.

\section{Results}

Use of chemotherapy

Of women deemed eligible for chemotherapy, 836 (69\%) women had received chemotherapy. No significant differences in rates of chemotherapy use were observed between Māori and NZ European women (68.3\% vs. $68.7 \%, p=0.916)$. Chemotherapy use was significantly higher in women of younger age groups $(p<0.001)$, zero comorbidity score $(p<0.001)$, surgically treated in private hospitals $(p=0.002)$ and non-screen detected cancer $(p=0.033)$ (Table 1). Increasing socioeconomic deprivation tended to be associated with a lower use of chemotherapy, although this was not statistically significant $(p=0.402)$. As expected, chemotherapy use was higher for cancers which were associated with adverse prognostic characteristics, which included $\geq 5 \mathrm{~cm}$ in diameter, positive lymph node status, higher grade, lymphovascular invasion (LVI) and HER-2 positivity. Trends in use of chemotherapy by tumour characteristics were observed to be similar for Māori and NZ European women. Among these women deemed eligible for chemotherapy, no significant differences in the distribution of tumour biological characteristics between Maori and NZ European women were observed (Data not shown).

Multivariate analysis of factors associated with chemotherapy use is shown in Table 2. Age, comorbidity score and adverse tumour characteristics remained significant while socio-demographic factors and surgical hospital type were not significant.

An additional analysis was performed with a different chemotherapy threshold for ER and/or PR positive cancers, considering these cancers as eligible for chemotherapy only if the cancer had one or more of lymph node positivity, lympho-vascular invasion or tumour grade $\geq 2$ in addition to a maximum tumour diameter of $\geq 20 \mathrm{~mm}$. This analysis yielded results much similar to the analysis in Table 1 (data not shown). According to new criteria, 
Table 1 Socio-demographic and tumour characteristics associated with use of adjuvant chemotherapy ${ }^{a}$

\begin{tabular}{|c|c|c|c|c|c|}
\hline \multirow{3}{*}{ Characteristic } & \multirow{3}{*}{$\begin{array}{l}\text { Total population }(N=1212) \\
n(\%)\end{array}$} & \multicolumn{4}{|c|}{ Use of chemotherapy } \\
\hline & & \multicolumn{2}{|c|}{ Total chemotherapy $(N=1212)$} & \multirow{2}{*}{$\begin{array}{l}\text { NZ European }(N=924) \\
n(\%)^{b}\end{array}$} & \multirow{2}{*}{$\begin{array}{l}\text { Māori }(N=218) \\
n(\%)^{b}\end{array}$} \\
\hline & & $n(\%)^{\mathrm{b}}$ & $p$ & & \\
\hline Overall & $1212(100)$ & $836(69.0)$ & & $635(68.7)$ & $149(68.3)$ \\
\hline Age (yrs.) & & & $<0.001$ & & \\
\hline$<40$ & $100(8.3)$ & $90(90.0)$ & & $58(89.2)$ & $18(90.0)$ \\
\hline $40-49$ & $338(27.9)$ & $276(81.7)$ & & $200(81.3)$ & $56(81.2)$ \\
\hline $50-59$ & $434(35.8)$ & $309(71.2)$ & & $245(72.5)$ & $53(68.8)$ \\
\hline $60-69$ & $340(28.1)$ & $161(47.4)$ & & $132(48.0)$ & $22(42.3)$ \\
\hline Deprivation & & & 0.402 & & \\
\hline Dep 1-2 & $139(11.5)$ & $100(71.9)$ & & $88(71.5)$ & $8(80.0)$ \\
\hline Dep 3-4 & $126(10.4)$ & $89(70.6)$ & & $72(70.6)$ & $12(75.0)$ \\
\hline Dep 5-6 & $313(25.8)$ & $216(69.0)$ & & $174(67.7)$ & $29(70.7)$ \\
\hline Dep 7-8 & $315(26.0)$ & $213(67.6)$ & & $160(67.8)$ & $39(61.9)$ \\
\hline Dep 9-10 & $319(26.3)$ & $218(68.3)$ & & $141(68.4)$ & $61(69.3)$ \\
\hline Surgical hospital type & & & 0.002 & & \\
\hline Private & $406(33.5)$ & $303(74.6)$ & & $271(74.0)$ & $21(80.8)$ \\
\hline Public & $806(66.5)$ & $533(66.1)$ & & $364(65.2)$ & $128(66.7)$ \\
\hline Diagnostic type & & & 0.033 & & \\
\hline Screen detected & 407 (33.6) & $235(57.7)$ & & $195(57.9)$ & $30(57.7)$ \\
\hline Non-screen detected & $805(66.4)$ & $601(74.7)$ & & $440(75.0)$ & $119(71.7)$ \\
\hline Charlson score & & & $<0.001$ & & \\
\hline 0 & $1056(87.1)$ & $754(71.4)$ & & $582(70.5)$ & $124(71.7)$ \\
\hline $1+$ & $156(12.9)$ & $82(52.6)$ & & $53(53.5)$ & $25(55.6)$ \\
\hline Diagnosis year & & & 0.003 & & \\
\hline 1999-2002 & $269(22.2)$ & $201(74.7)$ & & $160(73.7)$ & $31(79.5)$ \\
\hline $2003-2006$ & $374(30.9)$ & 267 (71.4) & & $216(72.5)$ & $38(66.7)$ \\
\hline 2007-2009 & $292(24.1)$ & $183(62.7)$ & & $128(60.7)$ & $39(65.0)$ \\
\hline 2010-2012 & 277 (22.9) & $185(66.8)$ & & $131(66.2)$ & $41(66.1)$ \\
\hline Grade & & & $<0.001$ & & \\
\hline Grade I & $168(13.9)$ & $70(41.7)$ & & $62(43.4)$ & $6(33.3)$ \\
\hline Grade ॥ & $617(50.9)$ & $409(66.3)$ & & $305(66.0)$ & $83(66.9)$ \\
\hline Grade III & $395(32.6)$ & $340(86.1)$ & & $254(85.8)$ & $57(83.8)$ \\
\hline Missing & $32(2.6)$ & $17(53.1)$ & & $14(60.9)$ & $3(37.5)$ \\
\hline ER/PR status & & & $<0.001$ & & \\
\hline ER \&/or PR + & $926(76.4)$ & $598(64.6)$ & & $457(64.3)$ & $103(63.6)$ \\
\hline$E R \& P R-$ & $276(22.8)$ & $233(84.4)$ & & $173(84.4)$ & 46 (83.6) \\
\hline Missing & $10(0.8)$ & $5(50.0)$ & & $5(62.5)$ & 0 \\
\hline T stage & & & $<0.001$ & & \\
\hline $\mathrm{T} 1$ & $368(30.4)$ & $234(63.6)$ & & $196(62,6)$ & $29(69.0)$ \\
\hline $\mathrm{T} 2$ & $692(57.1)$ & $484(69.9)$ & & $364(71.4)$ & $83(62.4)$ \\
\hline T3 & $83(6.8)$ & $64(77.1)$ & & $40(74.1)$ & 19 (82.6) \\
\hline T4 & $62(5.1)$ & $50(80.6)$ & & 31 (77.5) & $18(90.0)$ \\
\hline Missing & $7(0.6)$ & $4(55.6)$ & & $4(55.6)$ & 0 \\
\hline N stage & & & $<0.001$ & & \\
\hline
\end{tabular}


Table 1 Socio-demographic and tumour characteristics associated with use of adjuvant chemotherapy ${ }^{\mathrm{a}}$ (Continued)

\begin{tabular}{|c|c|c|c|c|c|}
\hline 0 & $406(33.5)$ & $223(54.9)$ & & $165(54.6)$ & $37(50.0)$ \\
\hline 1 & $537(44.3)$ & 381 (70.9) & & $291(70.0)$ & $72(74.2)$ \\
\hline $2+$ & $269(22.2)$ & $232(86.2)$ & & $179(86.9)$ & $40(85.1)$ \\
\hline LVI & & & $<0.001$ & & \\
\hline Negative & 783 (64.6) & $484(61.8)$ & & $362(61.0)$ & $88(62.0)$ \\
\hline Positive & $429(35.4)$ & $352(82.1)$ & & $273(82.5)$ & $61(80.3)$ \\
\hline HER-2 & & & $<0.001$ & & \\
\hline Negative & $658(54.3)$ & $414(62.9)$ & & $314(63.2)$ & 79 (60.8) \\
\hline Equivocal & $48(4.0)$ & $25(52.1)$ & & $17(48.6)$ & $6(66.7)$ \\
\hline Positive & $219(18.1)$ & $188(85.8)$ & & $134(86.5)$ & $37(80.4)$ \\
\hline Missing & $287(23.7)$ & 209 (72.8) & & $170(71.7)$ & 27 (81.8) \\
\hline
\end{tabular}

${ }^{a}$ Only ER and PR negative cancers $\geq 10 \mathrm{~mm}$ and ER and/or PR positive cancers $\geq 20 \mathrm{~mm}$ in women $<70$ years are included

${ }^{\mathrm{b}}$ Proportion of women who had received chemotherapy in each category

Table 2 Multivariable logistic regression analysis for factors associated with use of adjuvant chemotherapy (Number of patients included in the regression analysis $=1064$ [87.8\%])

\begin{tabular}{|c|c|c|c|}
\hline Characteristic & OR & $95 \% \mathrm{Cl}$ & $p$ \\
\hline Māori ethnicity ${ }^{a}$ & 1.02 & $0.90-1.14$ & 0.934 \\
\hline $\mathrm{Age}^{\mathrm{b}}$ & 0.92 & $0.91-0.94$ & $<0.001$ \\
\hline Year of diagnosis ${ }^{c}$ & 0.94 & $0.88-1.02$ & 0.122 \\
\hline ER and/or PR positive ${ }^{d}$ & 0.34 & $0.21-0.57$ & $<0.001$ \\
\hline Deprivation $^{\mathrm{e}}$ & 0.98 & $0.87-1.11$ & 0.733 \\
\hline Charlson score & 0.34 & $0.17-0.60$ & $<0.001$ \\
\hline Surgery in public vs. private & 1.07 & $0.77-1.49$ & 0.688 \\
\hline \multicolumn{4}{|l|}{ T stage ${ }^{f}$} \\
\hline T2 & 1.58 & $1.12-2.23$ & 0.009 \\
\hline T 3 & 1.47 & $0.65-2.49$ & 0.486 \\
\hline T 4 & 1.23 & $0.41-3.41$ & 0.876 \\
\hline \multicolumn{4}{|l|}{$N$ stage $^{g}$} \\
\hline N 1 & 2.49 & $1.71-3.64$ & $<0.001$ \\
\hline N 2+ & 8.41 & $4.37-16.2$ & $<0.001$ \\
\hline \multicolumn{4}{|l|}{ Grade $^{h}$} \\
\hline Grade II & 2.41 & $1.58-3.70$ & $<0.001$ \\
\hline Grade III & 4.79 & $2.87-7.99$ & $<0.001$ \\
\hline$L V I^{i}$ & 1.78 & $1.22-2.61$ & $<0.001$ \\
\hline \multicolumn{4}{|l|}{ HER- $2^{j}$} \\
\hline HER-2 Equivocal & 0.55 & $0.26-1.15$ & 0.116 \\
\hline HER-2 Positive & 2.02 & $1.23-3.33$ & 0.006 \\
\hline HER-2 Unknown & 1.36 & $0.83-2.24$ & 0.548 \\
\hline
\end{tabular}

${ }^{a}$ Maori compared with NZ European ethnicity

${ }^{\mathrm{b}}$ Age as a continuous variable

${ }^{\text {'}}$ Year of diagnosis as a continuous variable

${ }^{d} E R$ and/or PR positive compared with ER \& PR negative

eDeprivation as a continuous variable

${ }^{f}$ Reference category $\mathrm{T} 1$ stage

${ }^{9}$ Reference category N0 stage

${ }^{\mathrm{h}}$ Reference category Grade I

'Reference category LVI negative

${ }^{\mathrm{j}}$ Reference category HER-2 negative
1168 women were found to be eligible, and of this 824 (70.5\%) had received chemotherapy; 623 (70.1\%) of NZ European and 149 (70.3\%) of Māori women. Multivariable logistic regression analysis showed trends similar to Table 2 and, for Mãori, the adjusted odds for receiving chemotherapy was $1.25(0.85-1.87, p=0.258)$.

\section{Use of radiotherapy}

Characteristics associated with use of radiotherapy are shown in Table 3. Overall, radiotherapy was used for 1491 (87.3\%) of women deemed to be eligible for radiation based on selection criteria. Radiotherapy use was lower in Māori compared with NZ European women ( $84 \%$ vs. $87.8 \%, p=0.138)$, but the difference was statistically not significant. Younger age at diagnosis, lower socioeconomic deprivation, later year of diagnosis, surgical care in a private hospital, shorter distance from the hospital, screen detection, undergoing BCS and adverse tumour characteristics including higher grade, stage and positive axillary lymph node status were significantly associated with increased likelihoods of receiving radiotherapy.

Multivariable regression analysis of factors associated with radiotherapy use is shown in Table 4. Māori compared with NZ European ethnicity (OR $=0.63,95 \% \mathrm{CI}, 0.40-0.98)$, older age (OR $=0.96,95 \%$ CI $0.95-0.98)$, distance of over $100 \mathrm{~km}$ from the radiation facility $(\mathrm{OR}=0.47,95 \% \mathrm{CI}, 0.23$ 0.96, higher comorbidity score $(\mathrm{OR}=0.49,95 \% \mathrm{CI}$, 0.34-0.72), mastectomy compared with $\mathrm{BCS}(\mathrm{OR}=0.32$, 95\% CI, 0.17-0.57) and non-screen compared with screen detection $(\mathrm{OR}=0.53,95 \% \mathrm{CI}, 0.35-0.79)$ were significantly associated with lower likelihoods of receiving radiotherapy in this model.

Further analyses were performed for women undergoing BCS and mastectomy separately (Data not shown). These analyses confirmed that Māori were less likely to have received radiation following mastectomy $(\mathrm{OR}=0.54,0.24$ $1.22, p=0.134)$ and $\mathrm{BCS}(\mathrm{OR}=0.70,0.41-1.43, p=0.402)$, 
Table 3 Socio-demographic and tumour characteristics associated with use of adjuvant radiotherapy

\begin{tabular}{|c|c|c|c|c|c|}
\hline \multirow{3}{*}{ Characteristic } & \multirow{3}{*}{$\begin{array}{l}\text { Total population }(N=1708) \\
n(\%)\end{array}$} & \multicolumn{4}{|c|}{ Use of radiotherapy } \\
\hline & & \multicolumn{2}{|c|}{ Total $(N=1708)$} & \multirow{2}{*}{$\begin{array}{l}\text { NZ European }(N=1418) \\
n(\%)^{a}\end{array}$} & \multirow{2}{*}{$\begin{array}{l}\text { Māori }(N=225) \\
n(\%)^{a}\end{array}$} \\
\hline & & $\overline{n(\%)^{\mathrm{a}}}$ & $p$ & & \\
\hline Overall & 1708 & $1491(87.3)$ & & $1255(87.8)$ & $189(84.0)$ \\
\hline Age (yrs.) & & & $<0.001$ & & \\
\hline$<40$ & $79(4.6)$ & $76(96.2)$ & & $50(96.2)$ & $16(94.1)$ \\
\hline $40-49$ & $328(19.2)$ & $302(92.1)$ & & $231(93.9)$ & $52(86.7)$ \\
\hline $50-59$ & $499(29.2)$ & $456(91.4)$ & & $377(92.0)$ & $66(90.4)$ \\
\hline $60-69$ & $471(27.6)$ & 417 (88.5) & & $361(90.5)$ & $45(75.0)$ \\
\hline $70-79$ & $218(12.8)$ & $172(78.9)$ & & $161(78.9)$ & $8(72.7)$ \\
\hline $80+$ & $113(6.6)$ & $68(60.2)$ & & $65(60.7)$ & $2(50.0)$ \\
\hline Diagnosis year & & & 0.003 & & \\
\hline 1999-2002 & 357 (20.9) & $296(82.9)$ & & $255(83.9)$ & $30(76.9)$ \\
\hline $2003-2006$ & $506(29.6)$ & $443(87.5)$ & & $396(88.0)$ & $37(86.0)$ \\
\hline 2007-2009 & 406 (23.8) & $354(87.2)$ & & $284(87.4)$ & $50(84.7)$ \\
\hline 2010-2012 & $439(25.7)$ & $398(90.7)$ & & $310(91.4)$ & $72(85.7)$ \\
\hline Deprivation & & & 0.006 & & \\
\hline Dep 1-2 & $178(10.4)$ & $167(93.8)$ & & $156(94.0)$ & $5(83.3)$ \\
\hline Dep 3-4 & $186(10.9)$ & $163(87.6)$ & & $140(87.5)$ & $17(94.4)$ \\
\hline Dep 5-6 & $414(24.2)$ & $364(87.9)$ & & $318(88.1)$ & $37(90.2)$ \\
\hline Dep 7-8 & $491(28.7)$ & $423(86.2)$ & & $356(87.9)$ & $54(77.1)$ \\
\hline Dep 9-10 & $439(25.7)$ & $374(85.2)$ & & $275(84.4)$ & $76(84.4)$ \\
\hline Distance & & & 0.005 & & \\
\hline$<10 \mathrm{~km}$ & $546(32.0)$ & 489 (89.6) & & $409(90.5)$ & $54(85.7)$ \\
\hline $10-50 \mathrm{~km}$ & 660 (38.6) & $579(89.1)$ & & $488(88.1)$ & 70 (85.6) \\
\hline $50-100 \mathrm{~km}$ & $428(25.1)$ & $364(85.0)$ & & $310(85.4)$ & 49 (83.1) \\
\hline$>100 \mathrm{~km}$ & $74(4.3)$ & $59(79.7)$ & & $38(79.2)$ & $16(76.2)$ \\
\hline \multicolumn{6}{|l|}{ Missing } \\
\hline Diagnostic type & & & $<0.001$ & & \\
\hline Screen detected & 750 (43.9) & $698(93.1)$ & & 602 (93.3) & $76(90.5)$ \\
\hline Symptomatic & $958(56.1)$ & 793 (82.8) & & $643(83.2)$ & $113(80.1)$ \\
\hline Hospital type & & & $<0.001$ & & \\
\hline Private & 535 (31.3) & $488(91.2)$ & & $453(91.5)$ & $25(86.2)$ \\
\hline Public & $1173(68.7)$ & 1003 (85.5) & & $792(85.8)$ & 164 (83.7) \\
\hline Surgery type & & & $<0.001$ & & \\
\hline $\mathrm{BCS}$ & $1354(79.3)$ & $1213(89.6)$ & & $1031(89.7)$ & $143(88.8)$ \\
\hline Mastectomy & $354(20.7)$ & $278(78.5)$ & & $214(79.9)$ & $46(71.9)$ \\
\hline Grade & & & 0.493 & & \\
\hline Grade I & $441(25.8)$ & $381(86.4)$ & & $341(87.0)$ & $27(79.4)$ \\
\hline Grade II & 865 (50.6) & 754 (87.2) & & $626(88.0)$ & $102(82.9)$ \\
\hline Grade III & $371(21.7)$ & $331(89.2)$ & & $257(89.2)$ & $56(87.5)$ \\
\hline Unknown & $31(1.8)$ & $25(80.6)$ & & $21(77.8)$ & $4(100)$ \\
\hline T stage & & & $<0.001$ & & \\
\hline $\mathrm{T} 1$ & $1020(59.7)$ & 915 (90.1) & & $790(90.1)$ & $98(89.9)$ \\
\hline $\mathrm{T} 2$ & $518(30.3)$ & 437 (84.4) & & $356(85.8)$ & $57(76.0)$ \\
\hline
\end{tabular}


Table 3 Socio-demographic and tumour characteristics associated with use of adjuvant radiotherapy (Continued)

\begin{tabular}{|c|c|c|c|c|c|}
\hline $\mathrm{T3}$ & $100(5.9)$ & $79(79.0)$ & & $54(76.1)$ & $20(87.0)$ \\
\hline $\mathrm{T} 4$ & $70(4.1)$ & $58(82.9)$ & & $43(84.3)$ & $14(77.8)$ \\
\hline N stage & & & 0.042 & & \\
\hline 0 & $1029(60.3)$ & $900(87.8)$ & & $762(87.8)$ & 106 (86.9) \\
\hline 1 & $363(21.2)$ & $321(88.9)$ & & $266(90.2)$ & $45(83.3)$ \\
\hline $2+$ & $316(18.5)$ & $266(84.2)$ & & $215(93.1)$ & $36(76.6)$ \\
\hline Charlson score & & & $<0.001$ & & \\
\hline 0 & $1456(85.2)$ & $1312(90.1)$ & & 1111 (90.7) & $151(85.8)$ \\
\hline $1+$ & $252(14.8)$ & $179(71.0)$ & & $134(69.4)$ & $38(77.6)$ \\
\hline
\end{tabular}

aProportion of women who had received radiotherapy in each category

although these differences were not statistically significant. Significantly lower likelihoods of receiving radiation following both BCS and mastectomy were seen for women of older age $(\mathrm{OR}=0.94,95 \% \mathrm{CI} 0.92-0.96$ and $\mathrm{OR}=0.95$, 95\% CI 0.93-0.97 respectively), non-screen compared with screen detected $(\mathrm{OR}=0.43,95 \% \mathrm{CI}, 0.31-0.55$ and $\mathrm{OR}=0.72$, 95\% CI 0.31-1.70, respectively) and for

Table 4 Multivariable logistic regression analysis for factors associated with use of adjuvant radiotherapy (Number of patients included in the regression analysis = 1643 [96.2\%])

\begin{tabular}{|c|c|c|c|}
\hline Characteristic & $\mathrm{OR}$ & $95 \% \mathrm{Cl}$ & $p$ \\
\hline Māori ethnicity ${ }^{a}$ & 0.63 & $0.40-0.98$ & 0.040 \\
\hline $\mathrm{Age}^{\mathrm{b}}$ & 0.96 & $0.95-0.98$ & $<0.001$ \\
\hline Year of diagnosis ${ }^{c}$ & 1.07 & $1.02-1.11$ & 0.004 \\
\hline Deprivation $^{d}$ & 0.92 & $0.79-1.06$ & 0.232 \\
\hline \multicolumn{4}{|l|}{ Distance $e^{e}$} \\
\hline $10-50 \mathrm{~km}$ & 0.74 & $0.50-1.09$ & 0.130 \\
\hline $50-100 \mathrm{~km}$ & 0.67 & $0.44-1.03$ & 0.067 \\
\hline$>100 \mathrm{~km}$ & 0.47 & $0.23-0.96$ & 0.040 \\
\hline Charlson score $\mathrm{f}^{\mathrm{f}}$ & 0.49 & $0.34-0.72$ & $<0.001$ \\
\hline Surgery in public vs. private & 0.86 & $0.61-1.26$ & 0.467 \\
\hline Non-screen vs. screen detection & 0.53 & $0.35-0.79$ & 0.002 \\
\hline Mastectomy vs. BCS & 0.32 & $0.17-0.57$ & $<0.001$ \\
\hline \multicolumn{4}{|l|}{ T stage ${ }^{g}$} \\
\hline T 2 & 0.84 & $0.57-1.24$ & 0.394 \\
\hline T3 & 1.09 & $0.53-2.24$ & 0.809 \\
\hline T 4 & 1.42 & $0.66-3.07$ & 0.366 \\
\hline \multicolumn{4}{|l|}{$N$ stage $^{h}$} \\
\hline N 1 & 1.45 & $0.94-2.24$ & 0.093 \\
\hline N $2+$ & 2.66 & $1.38-5.10$ & 0.003 \\
\hline
\end{tabular}

Maori compared with NZ European ethnicity

${ }^{\mathrm{b}}$ Age as a continuous variable

'Year of diagnosis as a continuous variable

${ }^{d}$ Deprivation as a continuous variable

${ }^{\mathrm{e}}$ Reference category Distance $<10 \mathrm{~km}$

${ }^{\mathrm{f}}$ Reference category Charlson score $=0$

${ }^{9}$ Reference category $\mathrm{T} 1$ stage

${ }^{\mathrm{h}}$ Reference category No stage women with comorbidity $(\mathrm{OR}=0.32,95 \%$ CI 0.21 0.43 and $\mathrm{OR}=0.28,95 \% \mathrm{CI} 0.16-0.52$, respectively).

\section{Discussion}

This study has shown that use of adjuvant radiotherapy has been significantly lower in Indigenous Māori compared with NZ European women with breast cancer, based on accepted practice guidelines over the study period [13, 14]. No significant difference in the use of chemotherapy was observed between Māori and NZ European women. Further, significantly lower use of radiotherapy was seen among rural compared with urban dwelling women and non-screen compared with screen detected women. Overall, the use of radiation was lower than expected based on guidelines [13, 14], and was substantially worse for post-mastectomy radiation (78.5\%) than for radiation following BCS (89.6\%). Although the use of radiotherapy seems to have increased over time, a substantial proportion of potentially eligible women (9\%) have not received radiation even during 2010-2012.

Lower use of adjuvant chemotherapy in minority ethnic cancer patients are well documented in the USA, and include lower use of chemotherapy for breast, colon and lung among many other cancers [21, 22]. Not only that these patients have experienced lower use of adjuvant chemotherapy, but on many occasions were subjected to longer delays and use of chemotherapy regimens not in keeping with recommended guidelines [23-25]. Similarly, lower use and longer delays for adjuvant chemotherapy for bowel cancer in Māori compared with non-Māori patients have supported the existence of similar ethnic disparities in New Zealand [7]. Despite that, we did not observe a significant difference between Māori and NZ European women in the use of adjuvant chemotherapy for breast cancer, either in univariate or multivariate models. However, a previous analysis based on the WBCR found that Māori women were significantly more likely to experience longer delays for initiation of chemotherapy than for NZ European women 
[9]. Further, we have not analysed the use of recommended regimens of chemotherapy or rates of completion of chemotherapy in the present study. Hence, although we have not observed an ethnic disparity in overall adjuvant chemotherapy use, further research is needed to investigate possible disparities in other areas of chemotherapy use including rates of completion and use of recommended regimens.

Overall, use of radiotherapy fell short of recommended guidelines, and was significantly lower for Māori compared with NZ European women [13, 14]. Similar inequities in the use of adjuvant radiotherapy for breast cancer have been reported from the USA, between minority African American and White American women [21, 26]. It appears that socio-demographically disadvantaged women (i.e. Mãori, rural residence and high socioeconomic deprivation) had higher likelihoods of not receiving adjuvant radiation, while no such differences were observed for chemotherapy. Differences in difficulty in accessing radiotherapy in comparison to chemotherapy might have at least partially been responsible for this difference. Adjuvant radiation for the study population was provided through the central radiation facility at the tertiary hospital in Hamilton. As radiotherapy requires attending a radiation facility five days a week over a period, ranging from four to six weeks, for women residing in remote and rural areas this would have posed a significant barrier due to difficulties with time and cost of travel. Many rural women with breast cancers suitable for BCS opting for mastectomy due to similar reasons is well documented in the literature [27]. Women of low socioeconomic groups also face similar barriers due to difficulties with transport, taking time off work or due to lack of support to care for dependants, resulting in lower use of radiotherapy [28]. Higher proportions of Māori live in rural areas and are more likely to be socioeconomically deprived contributing to lower radiotherapy use in Mãori. However, Maori ethnicity appears to be an independent risk factor for lower use of radiotherapy as observed in the multivariate model.

Women with screen detected cancer were significantly more likely to have received radiotherapy compared to women with non-screen detected women, a common pattern following both mastectomy and BCS. Diagnostic and treatment indicators for women diagnosed through BSA programme are routinely measured and performance of each screening provider is regularly audited against pre-established criteria. For instance, at least 95\% of women diagnosed through BSA are expected to have received radiotherapy following $\mathrm{BCS}$ for invasive cancer [29]. If a provider fails to achieve these targets corrective measures are initiated through a feedback process. However, similar quality measures or audit processes were non-existent for symptomatically detected cancer. This provides a likely explanation for higher radiotherapy rates seen for screen detected cancer, despite these cancers generally carrying a lower risk of local recurrence compared with non-screen detected cancer. This observation highlights a failure of the healthcare system, where women with lower risk cancers have likely been prioritized to receive treatment over women with higher risk cancers. Such inequities in care are likely to further exacerbate inequities in breast cancer outcomes seen between Māori and NZ European women, especially since Māori women have a significantly lower screening coverage [29], and as a result, a lower proportion of screen detected cancer.

Main strengths of this study include the completeness of the population based sample which included more than $98 \%$ of all breast cancers diagnosed in the Waikato region over the study period and comprehensive nature of the data included [15]. As the population distributions, provision of breast screening and treatment services in the Waikato region are much similar to rest of New Zealand, and hence findings from this study are likely to be representative of the whole country $[12,29,30]$.

However, there were several limitations. First, although we observed differences in adjuvant therapy among some groups of interest and several associations, we could not ascertain exact causes for non-use (i.e. not referred, not seen by an oncologist or patient declined) due to non-availability of this information from the WBCR. Selection of patients for chemotherapy is complicated and is based on multiple factors including age, tumour size, grade, ER/PR, lymph node status and lympho-vascular invasion. As a result, criteria used for eligibility for chemotherapy were not absolute, especially for women with ER/PR positive cancers. This is a likely reason for the much lower use of chemotherapy use in the selected population (69\%) compared with radiotherapy use $(87.3 \%)$, for which the eligibility criteria were less complicated. Further, no major differences in NZ treatment guidelines for the use of breast cancer adjuvant therapy was observed during the study period [13]. Hence, any impact of such changes in guidelines are unlikely to have influenced the study findings. As we did not observe major differences in distribution of tumour biological characteristics between Māori and NZ European women that might have influenced the use of chemotherapy, such factors are unlikely to have influenced patient selection for chemotherapy in a differential manner.

\section{Conclusion}

In conclusion, we observed significantly lower use of radiotherapy for Māori and women living at a distance of $>100 \mathrm{~km}$ from the hospital, although similar disparities were not observed for chemotherapy. Difficulties in 
accessing radiotherapy appeared to be a major contributor towards differences observed by ethnicity, geographic location and socioeconomic status. Failures of the healthcare system to providing equitable care were also evident by the discrepancy in radiotherapy seen between screen and non-screen detected women. Increasing availability and improving access for breast cancer adjuvant therapy for women who are at a higher risk of not receiving adjuvant therapy due to ethnicity, geography or socioeconomic position need to be recognized as priorities, which may help minimize breast cancer outcome inequities.

\section{Abbreviations}

BCS: Breast conserving surgery; BSA: BreastScreen Aotearoa; ER: Oestrogen receptor; HER 2: Human epidermal growth factor receptor type 2; NZ: New Zealand; NZDep06: New Zealand deprivation index 2006; OR: Odds ratio; PR: Progesterone receptor; TNM: Tumour, Node, Metastasis; WBCR: Waikato breast cancer register

\section{Acknowledgements}

None.

\section{Funding}

We acknowledge funding support received from the Waikato Breast Cancer Trust, the Cancer Society of New Zealand, the New Zealand Breast Cancer Foundation, the Lion Foundation, Grassroots Trust and the WEL energy trust for the WBCR and for additional data collection included for this study.

\section{Availability of data and materials}

Data will be made available on request by contacting the corresponding author.

\section{Authors' contributions}

SS developed the concept, designed the study, developed the methodology, collected data and performed the analysis. SS wrote up the initial version of the manuscript and IC, NS and RL provided comments. All authors contributed to the final version of the manuscript. All authors read and approved the final manuscript.

\section{Competing interests}

The authors declare that they have no competing interests.

\section{Consent for publication}

Not applicable.

\section{Ethics approval and consent to participate}

Ethical approval for this study was obtained from the New Zealand Northern 'A' Ethics Committee (Ref. No. 12/NTA/42). Individual patient consent was not required due to the observational nature of the study.

\section{Author details}

${ }^{1}$ Waikato Clinical School, University of Auckland, Hamilton, New Zealand. ${ }^{2}$ Māori Health Services, Waikato District Health Board, Hamilton, New

Zealand. ${ }^{3}$ Department of Surgery, University of Colombo, Colombo, Sri Lanka.

Received: 25 September 2015 Accepted: 17 January 2017

Published online: 21 January 2017

\section{References}

1. Li Cl, Malone KE, Daling JR. Differences in breast cancer stage, treatment, and survival by race and ethnicity. Arch Intern Med. 2003;163(1):49-56.

2. O'Malley CD, Le GM, Glaser SL, Shema SJ, West DW. Socioeconomic status and breast carcinoma survival in four racial/ethnic groups: a populationbased study. Cancer. 2003;97(5):1303-11.

3. Valery PC, Coory M, Stirling J, Green AC. Cancer diagnosis, treatment, and survival in Indigenous and non-Indigenous Australians: a matched cohort study. Lancet. 2006;367(9525):1842-8.
4. Bramley D, Hebert P, Jackson R, Chassin M. Indigenous disparities in diseasespecific mortality, a cross-country comparison: New Zealand, Australia, Canada, and the United States. N Z Med J. 2004;117(1207).

5. Freedman RA, He Y, Winer EP, Keating NL. Racial/Ethnic differences in receipt of timely adjuvant therapy for older women with breast cancer: are delays influenced by the hospitals where patients obtain surgical care? Health Serv Res. 2013;48(5):1669-83.

6. Freedman RA, Virgo KS, He Y, Pavluck AL, Winer EP, Ward EM, Keating NL. The association of race/ethnicity, insurance status, and socioeconomic factors with breast cancer care. Cancer. 2011;117(1):180-9.

7. Hill S, Sarfati D, Blakely T, Robson B, Purdie G, Dennett E, Cormack D, Dew K, Ayanian JZ, Kawachi I. Ethnicity and management of colon cancer in New Zealand: do indigenous patients get a worse deal? Cancer. 2010;116(13): 3205-14.

8. Seneviratne S, Campbell I, Scott N, Coles C, Lawrenson R. Treatment delay for Māori women with breast cancer in New Zealand. Ethn Health. 2015; 20(2):178-93.

9. Seneviratne S, Campbell I, Scott N, Kuper-Hommel M, Round G, Lawrenson R. Ethnic differences in timely adjuvant chemotherapy and radiation therapy for breast cancer in New Zealand: a cohort study. BMC Cancer. 2014;14(1):839.

10. Lawrenson R, Seneviratne S, Scott N, Peni T, Brown C, Campbell I. Breast cancer inequities between Mãori and non-Māori women in Aotearoa/New Zealand. Eur J Cancer Care. 2016;25(2):225-30.

11. Robson B, Purdie G, Cormack D: Unequal Impact II: Māori and Non-Māori Cancer Statistics by Deprivation and Rural-Urban Status 2002-2006. In Wellington: Ministry of Health; 2010

12. 2013 Census Data [http://www.stats.govt.nz/Census/2013-census/datatables/tables-about-a-place.aspx? request_value=24417\&tabname=]. Accessed 10 Nov 2015

13. New Zealand Guidelines Group: Management of early breast cancer - evidence based best practice guideline. In. Wellington: Ministry of Health; 2009

14. National Breast and Ovarian Cancer Centre: Clinical Practise Guidelines for the Management of Early Breast Cancer. In., 2nd edn. Australia: National Health and Medical Research Council (NHMRC), Australia; 2001.

15. Seneviratne S, Campbell I, Scott N, Shirley R, Peni T, Lawrenson R. Accuracy and completeness of the New Zealand Cancer Registry for staging of invasive breast cancer. Cancer Epidemiol. 2014;38(5):638-44.

16. American Joint Committee on Cancer: AJCC Cancer Staging Manual. In., 7th edn. New York: Springer-Verlag; 2010.

17. NZDep2006: Index of Deprivation. In.: Department of Public Health, University of Otago, Wellington. Ministry of Health; 2007.

18. Charlson ME, Pompei $P$, Ales $K L$, Mackenzie CR. A new method of classifying prognostic comorbidity in longitudinal studies: development and validation. J Chronic Dis. 1987:40(5):373-83.

19. Goldhirsch A, Ingle JN, Gelber R, Coates A, Thürlimann B, Senn H-J. Thresholds for therapies: highlights of the St Gallen International Expert Consensus on the primary therapy of early breast cancer 2009. Ann Oncol. 2009:20(8):1319-29.

20. IBM Corp: IBM SPSS Statistics for Windows, Version 22.0. In. Armonk, NY; 2013.

21. Bickell NA, Wang JJ, Oluwole S, Schrag D, Godfrey H, Hiotis K, Mendez J, Guth AA. Missed opportunities: racial disparities in adjuvant breast cancer treatment. J Clin Oncol. 2006:24(9):1357-62

22. Ayanian JZ, Zaslavsky AM, Fuchs CS, Guadagnoli E, Creech CM, Cress RD, O'Connor LC, West DW, Allen ME, Wolf RE, et al. Use of adjuvant chemotherapy and radiation therapy for colorectal cancer in a populationbased cohort. J Clin Oncol. 2003:21(7):1293-300.

23. Griggs JJ, Culakova E, Sorbero ME, Poniewierski MS, Wolff DA, Crawford J, Dale DC, Lyman GH. Social and racial differences in selection of breast cancer adjuvant chemotherapy regimens. J Clin Oncol. 2007; 25(18):2522-7.

24. Griggs JJ, Sorbero ME, Stark AT, Heininger SE, Dick AW. Racial disparity in the dose and dose intensity of breast cancer adjuvant chemotherapy. Breast Cancer Res Treat. 2003:81(1):21-31.

25. Smith K, Wray L, Klein-Cabral M, Schuchter L, Fox K, Glick J, DeMichele A. Ethnic disparities in adjuvant chemotherapy for breast cancer are not caused by excess toxicity in black patients. Clin Breast Cancer. 2005;6(3):260-6.

26. Curtis E, Quale C, Haggstrom D, Smith-Bindman R. Racial and ethnic differences in breast cancer survival: how much is explained by screening, tumor severity, biology, treatment, comorbidities, and demographics? Cancer. 2008;112(1):171-80. 
27. Schroen AT, Brenin DR, Kelly MD, Knaus WA, Slingluff CL. Impact of patient distance to radiation therapy on mastectomy use in early-stage breast cancer patients. J Clin Oncol. 2005;23(28):7074-80.

28. Gilligan MA, Kneusel RT, Hoffmann RG, Greer AL, Nattinger AB. Persistent differences in sociodemographic determinants of breast conserving treatment despite overall increased adoption. Med Care. 2002;40(3):181-9.

29. Page A, Morrell S, Taylor R: BreastScreen Aotearoa: Independent Monitoring Report, Screening and assessment report of women attending BSA. In. Wellington: National Screening Unit, Ministry of Health; 2014

30. Regional Cancer Networks [http://www.health.govt.nz/our-work/diseasesand-conditions/cancer-programme/regional-cancer-networks]. Accessed 10 Dec 2015

Submit your next manuscript to BioMed Central and we will help you at every step:

- We accept pre-submission inquiries

- Our selector tool helps you to find the most relevant journal

- We provide round the clock customer support

- Convenient online submission

- Thorough peer review

- Inclusion in PubMed and all major indexing services

- Maximum visibility for your research

Submit your manuscript at www.biomedcentral.com/submit
Biomed Central 